\title{
Estrogen deficiency induces bone loss by enhancing T-cell production of TNF- $\alpha$
}

\author{
Simone Cenci, ${ }^{1,2}$ M. Neale Weitzmann, ${ }^{1}$ Cristiana Roggia, ${ }^{1}$ Noriyuki Namba, ${ }^{3}$ \\ Deborah Novack, ${ }^{3}$ Jessica Woodring, ${ }^{1}$ and Roberto Pacifici ${ }^{1}$
}

${ }^{1}$ Division of Bone and Mineral Diseases, Washington University School of Medicine and Barnes-Jewish Hospital,
St. Louis, Missouri, USA
${ }^{2}$ Department of Gerontology and Geriatrics, University of Perugia, Perugia, Italy
${ }^{3}$ Department of Pathology, Washington University School of Medicine and Barnes-Jewish Hospital, St. Louis, Missouri, USA

Address correspondence to: Roberto Pacifici, Division of Bone and Mineral Diseases, Barnes-Jewish Hospital, North, 216 S. Kingshighway, St. Louis, Missouri 63110, USA. Phone: (314) 454-8407; Fax: (314) 454-5047; E-mail: Pacifici@im.wustl.edu.

Received for publication August 16, 2000, and accepted in revised form September 29, 2000.

Estrogen deficiency induces bone loss by upregulating osteoclastogenesis by mechanisms not completely defined. We found that ovariectomy-enhanced T-cell production of TNF- $\alpha$, which, acting through the TNF- $\alpha$ receptor $\mathrm{p} 55$, augments macrophage colony-stimulating factor-induced (M-CSF-induced) and RANKL-induced osteoclastogenesis. Ovariectomy failed to induce bone loss, stimulate bone resorption, or increase M-CSF- and RANKL-dependent osteoclastogenesis in T-cell deficient mice, establishing T cells as essential mediators of the bone-wasting effects of estrogen deficiency in vivo. These findings demonstrate that the ability of estrogen to target T cells, suppressing their production of TNF- $\alpha$, is a key mechanism by which estrogen prevents osteoclastic bone resorption and bone loss.

J. Clin. Invest. 106:1229-1237 (2000).

\section{Introduction}

Physiologic osteoclast renewal results from the differentiation of bone marrow monocytes (BMMs) into osteoclasts, a process induced by the simultaneous stimulation of osteoclast precursors by macrophage colonystimulating factor (M-CSF) and a TNF-related factor known as receptor activator of NF- $\mathrm{KB}$ ligand (RANKL; also known as OPGL, TRANCE, or ODF) (1-3).

Although upregulation of osteoclast formation is recognized as the main mechanism by which estrogen deficiency induces bone loss $(4,5)$, the responsible cells and cytokines are not completely understood. Bone marrow stromal cells are essential for physiologic osteoclast renewal because they represent a major source of RANKL and M-CSF and provide a physical support for nascent osteoclasts (6). However, in stimulated conditions additional bone marrow cells contribute to regulate osteoclast formation by producing soluble and membrane-bound pro- and antiosteoclastogenic cytokines. Among them are activated T cells, which stimulate osteoclast formation through increased production of RANKL, a phenomenon that contributes to inflammation-induced bone loss (7).

$\mathrm{T}$ cells express estrogen receptors, and estrogen directly regulates $\mathrm{T}$-cell function and cytokine production (8-11). Moreover, T-cell subset alterations occur in women with postmenopausal osteoporosis $(12,13)$. Taken together, these findings suggest that $\mathrm{T}$ cells may contribute to enhanced osteoclast formation and induce bone loss not only during inflammation, but also in conditions of estrogen deficiency.
In this study we have investigated the role of $\mathrm{T}$ cells in ovariectomy-induced bone loss. We report that ovariectomy-enhanced T-cell production of TNF- $\alpha$, which, acting through the TNF- $\alpha$ receptor $\mathrm{p} 55$, augments M-CSF- and RANKL-induced osteoclastogenesis. We also show that ovariectomy failed to induce bone loss, stimulate bone resorption, and increase osteoclast formation in T-cell deficient mice, establishing $\mathrm{T}$ cells as essential mediators of the bone-wasting effects of estrogen deficiency in vivo.

\section{Methods}

Experimental protocol. All animal procedures were approved by the Animal Care and Use Committee of Barnes-Jewish Hospital. Wild-type C57BL/6 mice, C57BL/6 homozygous ( $\mathrm{nu} / \mathrm{nu}$ ) athymic nude mice (14), and heterozygous $(n u /+)$ euthymic control littermates were obtained from Taconic Farms Inc. (Germantown, New York, USA). C57BL/ 6 mice lacking either TNF- $\alpha$ receptor $1\left(p 55^{-/-}\right)$or TNF- $\alpha$ receptor II $\left(p 75^{-/-}\right)$and wild-type controls of the same genetic background were obtained from Jackson Laboratories (Bar Harbor, Maine, USA). At 5 weeks of age mice were either sham operated or ovariectomized (OVX), and either left untreated or treated with $17 \beta$ estradiol $(0.16 \mu \mathrm{g} / \mathrm{d})$ for 4 weeks as described $(15,16)$.

In vitro osteoclast generation, cytokine neutralization, and TNF- $\alpha$ assay. Bone marrow cells were either cultured unfractionated or depleted of stromal cells by adherence for 12 hours. The nonadherent fraction was used as a source of T cells and BMM precursors and was found to 
be stromal cell free by using flow cytometry. T cells and BMMs were purified from bone marrow cells by positive immunoselection using MACS Microbeads (Miltenyi Biotec, Auburn, California, USA) coupled to anti-CD90 (Thy1.2) for $\mathrm{T}$ cells or anti-CD11b (Mac-1 $\alpha) \mathrm{Ab}$ for BMMs. This procedure, which does not result in either T-cell or BMM activation (17), was found to generate greater than $95 \%$ pure preparations of $\mathrm{CD}^{+} 0^{+}$and $\mathrm{CD}_{11} \mathrm{~b}^{+}$cells, as assessed by flow cytometry.

Bone marrow cells $\left(10^{6}\right.$ cells per well $)$ were cultured in 48 -well plates with $1,25(\mathrm{OH})_{2} \mathrm{D}_{3}\left(10^{-8} \mathrm{M}\right)$ for 7 days to induce osteoclast formation. Nonadherent cells $\left(10^{6}\right.$ cells per well) were incubated for 7 days in 48-well plates with recombinant murine M-CSF $(100 \mathrm{ng} / \mathrm{ml})$ and soluble RANKL (100 ng/ml), which, at these concentrations, were found to induce maximal osteoclast formation. BMMs ( $10^{5}$ cells per well), T cells $\left(10^{5}\right.$ cells per well), and cocultures of purified $\mathrm{BMM}^{+}$and $\mathrm{T}$ cells were incubated for 7 days in 96-well plates $(200 \mu \mathrm{l}$ of medium per well) with recombinant murine M-CSF $(100 \mathrm{ng} / \mathrm{ml})$ and soluble RANKL $(100 \mathrm{ng} / \mathrm{ml})$.

Culture media was collected after 3 days, and TNF$\alpha$ was measured using ELISA (Quantikine; R\&D Systems, Minneapolis, Minnesota, USA), as described (15). T-cell conditioned medium was prepared by culturing $10^{6} \mathrm{~T}$ cells $/ \mathrm{ml}$ for 3 days. T-cell conditioned medium $(100 \mu \mathrm{l})$ was added to a well containing $10^{5}$ BMMs and $100 \mu \mathrm{l}$ of fresh medium (50\% vol/vol). At days 3 and 5, $100 \mu$ l of the culture media was removed and replaced by $100 \mu \mathrm{l}$ of conditioned media so as to maintain a total volume of $200 \mu \mathrm{l}$ per well. TNFbp $(5 \mu \mathrm{g} / \mathrm{ml})$, IL-1ra $(50 \mu \mathrm{g} / \mathrm{ml}$; both kindly provided by Amgen Inc., Thousand Oaks, California, USA), and neutralizing anti-TNF- $\alpha$, anti-IL-1, and anti-IFN- $\gamma$ Ab's $(1 \mu \mathrm{g} / \mathrm{ml}$; R\&D Systems) were added at concentrations that are sufficient to neutralize (based on the manufacturer's specifications) greater than 1,000-fold concentration of TNF- $\alpha$, IL- 1 , and IFN- $\gamma$ found to be present in monocyte and T-cell cocultures.

At the end of each experiment, cells were fixed and stained for tartrate-resistant acid phosphatase (TRAP). More than $98 \%$ of the TRAP-positive cells with more than three nuclei expressed p $60^{\mathrm{c}-\mathrm{src}}$ and cathepsin $\mathrm{K}$, as assessed by immunohistochemistry, showed specific binding of labeled calcitonin, and formed resorption pits in vitro (assessed as described) (15). Thus, the TRAP-positive multinucleated cells formed in these cultures were defined as osteoclasts.

$T$-cell apoptosis assay. Annexin-V flow cytometry was used to measure T-cell apoptosis, using the Apoptest kit (NeXins Research BV, Hoeven, The Netherlands), according to the manufacturer's instructions. Briefly, $\mathrm{T}$ cells from OVX and estrogen-replete mice were cultured in Aim V medium (GIBCO BRL, Gaithersburg, Maryland, USA) for 48 hours before labeling with the early apoptosis indicator Annexin-V-FITC $(10 \mu \mathrm{l} / 106$ cells) and the vital stain propidium iodide $(10 \mu \mathrm{l}$ of a 50 $\mu \mathrm{g} / \mathrm{ml}$ stock). Cells were analyzed on a three-color Becton-Dickinson flow cytometer (FACScan; Franklin
Lakes, New Jersey, USA). To facilitate FACScan calibration and interpretation of data, a positive apoptosis control was generated by labeling $\mathrm{T}$ cells in the presence of $0.1 \%$ paraformaldehyde, which permeabilizes the membrane, simulating apoptosis. A dead-cell control was generated by exposing $\mathrm{T}$ cells to $0.1 \%$ sodium azide for 20 minutes before labeling with propidium iodide and Annexin-V. Data represent average plus or minus SD of triplicate runs.

Bone marrow T-cell content assay. The percentage of $\mathrm{T}$ cells in the bone marrow of sham, OVX, and estrogenreplaced OVX mice was examined using flow cytometry. Bone marrow cells were isolated from the femurs of sham, OVX, and estrogen-replaced OVX mice (five per group) using centrifugation. Briefly, bones were inserted into a $0.6-\mathrm{ml}$ microcentrifuge tube with a hole punctured in the bottom and placed into a $1.5-\mathrm{ml}$ carrier microcentrifuge tube. Cells were extracted from the bones by centrifugation at $10,000 \mathrm{~g}$ for 1 minute. Recovered bone marrow cells were counted on a hemocytometer for each group before 10-minute incubation in $20 \%$ normal goat serum to block Fc receptors. Cells were labeled with $\left(2 \mu \mathrm{g} / 10^{6}\right.$ cells) CD3-FITC Ab (Sigma Chemical Co., St. Louis, Missouri, USA) in labeling buffer (PBS containing 1\% BSA) for 40 minutes at $4^{\circ} \mathrm{C}$. Cells were washed once with labeling buffer and analyzed using flow cytometry on a three-color BectonDickinson flow cytometer (FACScan). Positive fluorescence was assessed by comparing the result to cells incubated in an irrelevant isotype Ab. The percentage of gated $T$ cells was multiplied by the total number of recovered cells from each group of mice to calculate the total number of $T$ cells per group.

$B M D$ and indices of bone remodeling. Trabecular bone mineral density (BMD) was measured in excised tibiae by peripheral quantitative computer tomography (pQCT) (XCT-960M; Nordland Medical Systems Inc., Fort Atkinson, Wisconsin, USA) as described (18), with modifications. Six cross-sections (two cortical at the mid-diaphysis and four trabecular at the proximal epiphysis) were scanned, and the data were analyzed using a threshold value of $200 \mathrm{mg} / \mathrm{cm}^{3}$ to select for bone and to exclude soft tissue. Cortical and trabecular bones were separated by "concentric peel" with the inner core (45\%) defined as trabecular bone. An inner bone-density threshold of 400 $\mathrm{mg} / \mathrm{cm}^{3}$ was selected to eliminate any residual or infiltrating cortical bone. Trabecular bone density $\left(\mathrm{mg} / \mathrm{cm}^{3}\right)$ was calculated using the internal software program CALCBD (Nordland Medical Systems Inc). The short-term in vitro reproducibility of this technique is $2 \%$.

Deoxypyridinoline (DPD) excretion was measured by ELISA using the Pyrilinks-D assay kit (Metra Biosystems Inc., Mountain View, California, USA) as described $(15,19)$. Serum osteocalcin levels were measured using the RIA kit of Biomedical Technologies Inc. (Stoughton, Massachusetts, USA).

Statistical analysis. Group mean values were compared by two-tailed Student's $t$ test or ANOVA and Fisher protected LSD test, as appropriate. 
Table 1

T cells from OVX mice increase osteoclast pit resorption activity

\begin{tabular}{|c|c|c|c|c|}
\hline & $\begin{array}{l}\text { BMMs } \\
\text { only }\end{array}$ & $\begin{array}{c}\text { BMMs } \\
+ \text { T cells } \\
\text { from } \\
\text { sham mice }\end{array}$ & $\begin{array}{l}\text { BMMs } \\
+ \text { T cells } \\
\text { from } \\
\text { untreated } \\
\text { OVX mice }\end{array}$ & $\begin{array}{c}\text { BMMs } \\
+ \text { T cells } \\
\text { from } \\
\text { estrogen-treatec } \\
\text { OVX mice }\end{array}$ \\
\hline $\begin{array}{l}\text { Number of pits } \\
\text { per slice }\end{array}$ & $25 \pm 5$ & $24 \pm 4$ & $69 \pm 9^{A}$ & $29 \pm 4$ \\
\hline
\end{tabular}

Dentine slices were placed on the bottom of 24 -well plates. BMMs $(2.5 \times$ $10^{5} /$ well) from nonoperated control mice, and T cells $\left(2.5 \times 10^{5} /\right.$ well $)$ from OVX and estrogen-replete mice were seeded on the dentine slices and cultured for 7 days in the presence of M-CSF and RANKL. The slices were then stained and the number of resorption pits counted as described (15). $n=6$ wells/per group. ${ }^{A} P<0.05$ compared with each of the other groups.

Table 2

Ovariectomy increases the percentage of T cells present in adherent bone marrow cells (mean \pm SEM)

\begin{tabular}{lccc}
\hline & $\begin{array}{c}\text { Sham } \\
\text { mice }\end{array}$ & $\begin{array}{c}\text { OVX } \\
\text { mice }\end{array}$ & $\begin{array}{c}\text { Estrogen-treated OVX } \\
\text { mice }\end{array}$ \\
$\begin{array}{l}\text { T cells } \\
\text { (\% of total } \\
\text { adherent cells) }\end{array}$ & $10.9 \pm 1.1$ & $21.8 \pm 2.3^{\mathrm{A}}$ & $15.0 \pm 2.0$ \\
\hline
\end{tabular}

Bone marrow from sham, OVX, and estrogen-treated OVX mice was subjected to Fycoll gradient as described (48). The mononuclear fraction was recovered and cultured for 2 hours. Adherent cells were then recovered and analyzed by FACS using anti-CD90 Ab as described in Methods. ${ }^{A} P<0.05$ compared with the other groups.

\section{Results}

Tcells mediate the increase in osteoclast formation induced by ovariectomy. To investigate the role of $\mathrm{T}$ cells in the increased osteoclastogenesis characteristic of estrogen deficiency, 5-week-old athymic nude $(n u / n u)$ mice, a strain that exhibits a profound T-cell deficiency (14), and control littermates $(n u /+)$ were either OVX or sham operated. OVX mice were either left untreated or treated with $17 \beta$ estradiol for 4 weeks. At the end of the 4-week treatment period, bone marrow was harvested and stimulated with $1,25(\mathrm{OH}) 2 \mathrm{D} 3$. At the end of each experiment, cells were fixed and stained for TRAP. More than 98\% of the TRAP-positive cells with more than three nuclei expressed pp60 ${ }^{c-s r c}$ and cathep$\sin \mathrm{K}$, showed specific binding of labeled calcitonin, and formed resorption pits in vitro. Thus, the TRAPpositive multinucleated cells formed in these cultures were defined as osteoclasts.

While in nude mice bone marrow from OVX and estrogen-replete animals (both sham operated and estrogen-treated OVX mice) generated an equal number of osteoclasts in euthymic mice, bone marrow from OVX animals formed twice as many osteoclasts as that from estrogen-replete (E2-replete) mice (Figure 1a), thus suggesting that $\mathrm{T}$ cells mediate the stimulatory effect of estrogen deficiency on osteoclast formation in vitro.

Contributing to the enhanced osteoclastogenesis of estrogen deficiency are increased production of $\mathrm{M}$ $\operatorname{CSF}(16,20)$ and blunted release of the RANKL decoy receptor osteoprotegerin (OPG) (21) from bone mar- row stromal cells. Since these cytokines are also produced by activated $\mathrm{T}$ cells (6), T lymphocytes from OVX mice may promote osteoclast formation through increased levels of M-CSF and free RANKL. However, analysis by RT-PCR revealed that T cells from OVX and estrogen-replete mice did not express detectable levels of M-CSF, RANKL, and OPG mRNAs (not shown), indicating that estrogen deficiency, unlike inflammation, does not induce the T-cell production of M-CSF and RANKL.

To determine if $\mathrm{T}$ cells from OVX mice increase osteoclast formation by enhancing the stromal-cell production of M-CSF and RANKL, nonadherent bone marrow cells (a stromal cell-depleted mixture of BMMs and lymphocytes) were stimulated with concentrations of RANKL and M-CSF, which maximally stimulate osteoclastogenesis. These experiments revealed that in euthymic mice osteoclast formation was still approximately twofold higher in cultures from OVX mice than in those from estrogen-replete mice. Confirming the regulatory function of T cells, in nude mice ovariectomy did not increase $\mathrm{M}-\mathrm{CSF}$ - and RANKL-induced osteoclast formation (Figure $1 \mathrm{~b}$ ). Thus, in conditions of estrogen deficiency $\mathrm{T}$ cells stimulate osteoclastogenesis through a mechanism unrelated to the presence of stromal cells and independent of regulation of OPG, RANKL, and M-CSF levels.

To further evaluate which cell population is the key target of estrogen in the bone marrow, BMMs (CD11 b ${ }^{+}$
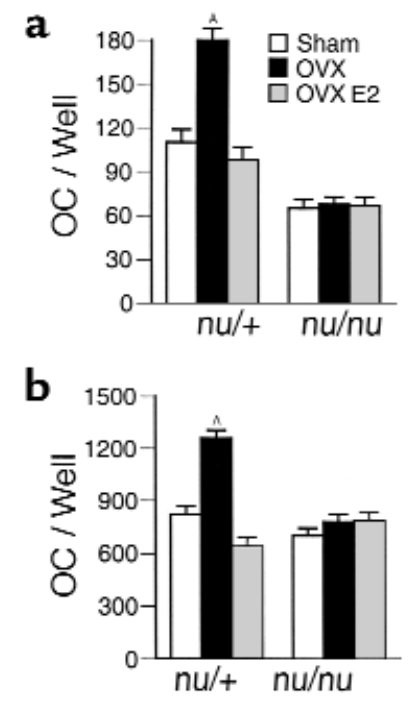

\section{Figure 1}

Ovariectomy fails to increase osteoclast formation in cultures of bone marrow cells from nude mice. Mean ( \pm SEM) number of osteoclasts from three independent experiments ( $n=6$ wells per group). ${ }^{A} P<0.05$ compared to estrogen replete mice. (a) Unfractionated bone marrow cells $\left(10^{6}\right.$ cells/well) from OVX and estrogen-replete nude and euthymic mice were harvested 4 weeks after surgery and cultured for 7 days with $1,25(\mathrm{OH})_{2} \mathrm{D}_{3}\left(10^{-8} \mathrm{M}\right)$ to induce osteoclast formation. (b) Bone marrow cells were depleted of stromal cells by adherence for 12 hours. Nonadherent bone marrow cells $\left(10^{6}\right.$ cells/well) were cultured for 7 days with optimal osteoclastogenic concentrations of M-CSF (25 $\mathrm{ng} / \mathrm{ml})$ and RANKL (100 ng/ml). OC, osteoclast. 

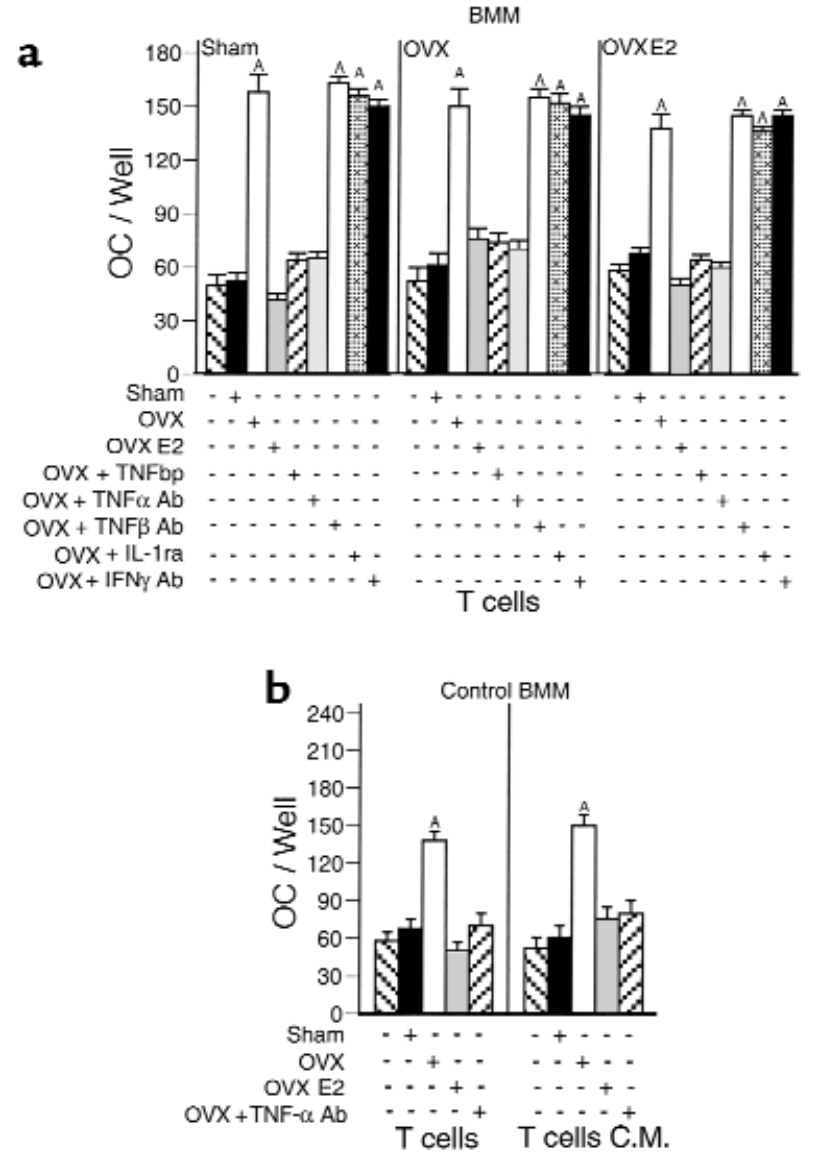

Figure 2

T cells from OVX mice produce a soluble factor upregulating RANKLand M-CSF-induced osteoclast formation, which is blocked by TNF$\alpha$ neutralization. Mean $( \pm$ SEM) of three independent experiments ( $n$ $=6$ wells per group). ${ }^{A} P<0.05$ compared with all other groups. (a) Cocultures of purified monocytes and purified T cells from OVX and estrogen-replete mice stimulated with optimal osteoclastogenic concentrations of M-CSF and RANKL. No osteoclast formation was observed in RANKL- and M-CSF-stimulated cultures of T cells in the absence of BMMs. Similarly, osteoclast differentiation of BMMs was not induced by stimulation with either RANKL or M-CSF alone, both in the presence or the absence of T cells (not shown). (b) Purified monocytes from intact mice stimulated with optimal osteoclastogenic concentrations of M-CSF and RANKL were cultured with either purified $T$ cells from OVX and estrogen-replete mice or $T$ cell-conditioned media (C.M.) from OVX and estrogen-replete mice. ${ }^{A} P<0.05 \mathrm{com}-$ pared with all other groups.

cells) and $\mathrm{T}$ cells (CD90 $0^{+}$cells) were purified using immunomagnetic-positive selection from the bone marrow of OVX and estrogen-replete wild-type mice. BMMs were stimulated with saturating amounts of RANKL and M-CSF and cultured for 7 days in the presence of $\mathrm{T}$ cells purified from mice of different experimental groups. M-CSF and RANKL induced the osteoclastic differentiation of BMMs, and the magnitude of this phenomenon was similar for BMMs from OVX and estrogen-replete mice (Figure 2a). Importantly, the addition of $\mathrm{T}$ cells from OVX mice to BMMs harvested from all groups of donor mice increased M-CSF- and
RANKL-induced osteoclast formation approximately 2.5 -fold. In contrast, the addition of $\mathrm{T}$ cells from estrogen-replete mice to BMMs from all groups, had no effect on osteoclast formation.

M-CSF and RANKL stimulated BMMs seeded on dentine slices differentiated into osteoclasts capable of forming resorption pits. Consistent with the ability of $\mathrm{T}$ cells from OVX mice to augment osteoclast formation, resorption pits were approximately 2.8 -fold more abundant in cocultures of BMMs and T cells from OVX mice, as compared with BMM cultured without $\mathrm{T}$ cells or cocultured with $\mathrm{T}$ cells from estrogen-replete mice (Table 1). Together, the data demonstrate that estrogen deficiency induces a T-cell activity capable of increasing the ability of M-CSF and RANKL to promote the formation of bone-resorbing osteoclasts.

Tcell-produced TNF- $\alpha$ induces osteoclast formation through the p55 TNF receptor. Neutralization experiments revealed that the ability of $\mathrm{T}$ cells from OVX mice to potentiate $\mathrm{M}-\mathrm{CSF}$ - and RANKL-induced osteoclast formation was completely prevented by the addition of either the TNF inhibitor, TNF-binding protein (TNFbp), or anti-TNF$\alpha \mathrm{Ab}$ (Figure 2a). In contrast, addition of either anti-TNF- $\beta$ Ab, the IL-1 inhibitor IL-1-receptor antagonist (IL-1ra), or anti-IFN- $\gamma \mathrm{Ab}$ had no effect.

Experiments conducted by stimulating BMMs with cell-free $\mathrm{T}$ cell-conditioned medium demonstrated that $\mathrm{T}$ cells from OVX mice secrete a soluble activity (neutralized by anti-TNF- $\alpha \mathrm{Ab}$ ) that enhances RANKL- and M-CSF-induced osteoclast differentiation of BMMs from nonoperated control mice (Figure

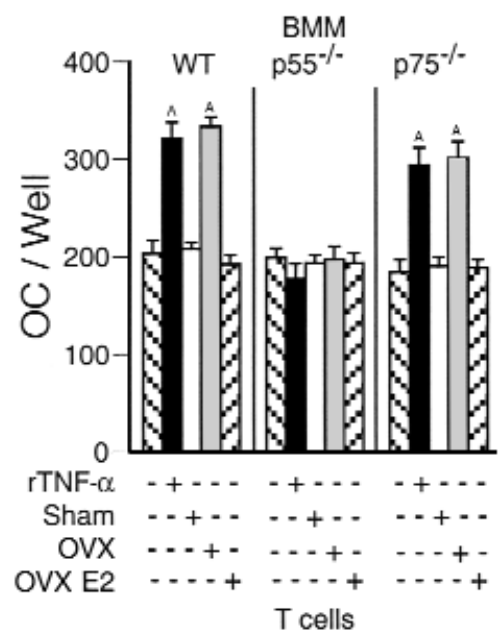

\section{Figure 3}

T cells from OVX mice fail to increase RANKL- and M-CSF-induced osteoclast differentiation of monocytes lacking the p55 TNF- $\alpha$ receptor. Mean $( \pm$ SEM) number of osteoclasts from three independent experiments ( $n=6$ wells per group). BMMs were purified from $\mathrm{C} 57 \mathrm{BL} / 6$ mice lacking either TNF- $\alpha$ receptor $1\left(p 55^{-/-}\right)$or TNF- $\alpha$ receptor II $\left(p 75^{-/-}\right)$and WT controls of the same genetic background and cocultured with $T$ cells derived from OVX or estrogen-replete WT mice in the presence of optimal concentrations of RANKL and M-CSF. ${ }^{A} P<0.05$ compared with all groups. 
$2 \mathrm{~b})$. These findings demonstrate that $\mathrm{T}$ cells from OVX mice upregulate osteoclast formation by production of soluble TNF- $\alpha$.

To determine if BMMs are the target of T cell-produced TNF- $\alpha, T$ cells from OVX and estrogen-replete mice were cocultured with BMMs from both mice lacking either the p55 or the p75 TNF- $\alpha$ receptor (22) and wild-type (WT) mice of the same genetic background. We found (Figure 3) that $\mathrm{T}$ cells from OVX mice increased M-CSF- and RANKL-induced osteoclast formation when cocultured with BMMs from either WT mice or mice lacking the p75 receptor, while failing to do so in the presence of BMMs lacking the TNF- $\alpha$ receptor $\mathrm{p} 55$. The accumulated data demonstrate that $\mathrm{T}$ cells from OVX mice augment osteoclast formation through secretion of TNF- $\alpha$ and its binding to the BMM TNF- $\alpha$ receptor $\mathrm{p} 55$.

Ovariectomy increases T cell-produced TNF- $\alpha$. Measurements by ELISA revealed (Figure 4a) the presence of approximately $200 \mathrm{pg} / \mathrm{ml}$ of TNF- $\alpha$ in the culture media of $\mathrm{T}$ cells from OVX mice, as compared with approximately $50 \mathrm{pg} / \mathrm{ml}$ in the media of T cells from estrogen-replete mice. BMMs from OVX and estrogenreplete mice produced similar amounts of TNF- $\alpha$ $(\sim 100 \mathrm{pg} / \mathrm{ml})$. As a result, TNF- $\alpha$ levels were (Figure $4 \mathrm{~b})$ approximately twofold higher $(\sim 300 \mathrm{pg} / \mathrm{ml})$ in the media from cocultures of T cells and BMMs from OVX mice than those from estrogen-replete mice $(\sim 150$ $\mathrm{pg} / \mathrm{ml}$ ). Confirming that $\mathrm{T}$ cells and BMMs are the major sources of TNF- $\alpha$ in the bone marrow, the levels of this cytokine in cultures of unstimulated whole bone marrow were approximately $300 \mathrm{pg} / \mathrm{ml}$ in samples from OVX mice and approximately 150 in those from estrogen-replete mice (Figure 4a).

In previous studies we observed that ovariectomy increased the production of TNF- $\alpha$ by adherent mononuclear cells, a semipurified monocyte preparation. Since in the current study we found no effect of ovariectomy on the production of TNF- $\alpha$ by highly purified BMMs, we used FACS analysis to determine the T-cell content of adherent bone marrow cell preparations. We found (Table 2) that adherent bone marrow cells contain $\mathrm{T}$ cells $(\sim 10 \%$ of total cells) and that ovariectomy increases $\mathrm{T}$-cell content approximately twofold. Taken together, the data suggest that the repressive effects of estrogen on adherent cell TNF- $\alpha$ secretion is due to decreased T-cell TNF- $\alpha$ production.

Dose-response studies revealed that recombinant TNF- $\alpha$ enhances M-CSF- and RANKL-induced osteoclast differentiation of $\mathrm{CD} 11 \mathrm{~b}^{+}$cells in a dose-dependent manner, with a peak activity at approximately 1.2 $\mathrm{ng} / \mathrm{ml}$ (Figure $4 \mathrm{c}$ ). While $200 \mathrm{pg} / \mathrm{ml}$ of TNF- $\alpha$ was ineffective, $300 \mathrm{pg} / \mathrm{ml}$ of TNF- $\alpha$ (the amount present in cocultures of BMMs and $\mathrm{T}$ cells from OVX mice) induced approximately a twofold increase in M-CSFand RANKL-induced osteoclast formation, thus demonstrating that the higher total level of TNF- $\alpha$ present in the culture media is responsible for the increase in osteoclast formation induced by T-cells from OVX mice. Levels of TNF- $\alpha$ up to $10 \mathrm{ng} / \mathrm{ml}$ did not induce osteoclast formation in the absence of RANKL.

Treatment of T cells from both OVX and estrogenreplete mice with $17 \beta$ estradiol for 48 hours did not decrease the levels of TNF- $\alpha$ in the culture media (Table 3 ), suggesting that estrogen regulates T-cell TNF- $\alpha$ pro-

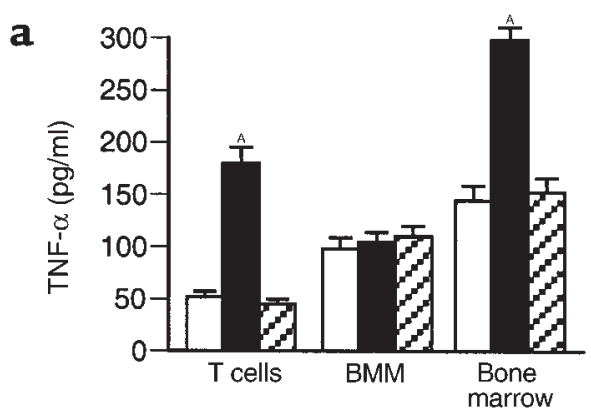

b

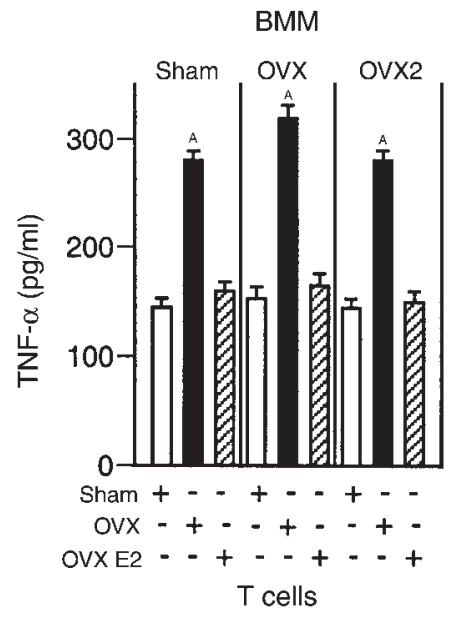

c

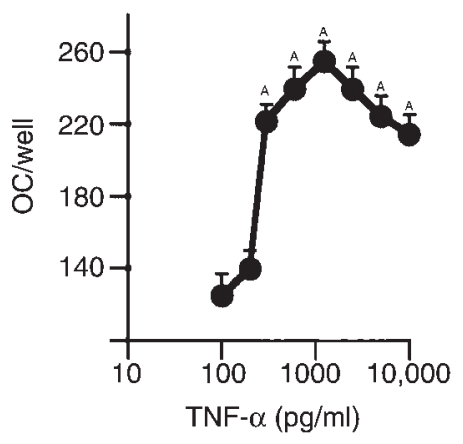

\section{Figure 4}

Ovariectomy increases T-cell secretion of TNF- $\alpha$. (a) TNF- $\alpha$ levels secreted by purified BMMs and T cells. Mean ( \pm SEM) levels in culture supernatants from three independent experiments $(n=6$ wells per group). $P<0.05$ compared with all other groups. Culture media was collected after 3 days and TNF- $\alpha$ measured by ELISA as described (15). (b) TNF- $\alpha$ levels in cocultures of BMMs and T cells. Mean $( \pm$ SEM) levels in culture supernatants from three independent experiments ( $n=6$ wells per group). $P<0.05$ compared with all other groups. (c) TNF- $\alpha$ augments RANKL- and M-CSF-induced osteoclast formation in a dose-dependent manner. Mean $( \pm$ SEM) number of osteoclasts from three independent experiments ( $n=6$ wells per dose). Purified monocytes from control mice were stimulated with M-CSF $(25 \mathrm{ng} / \mathrm{ml})$, RANKL (100 ng/ml), and TNF- $\alpha(0-10 \mathrm{ng} / \mathrm{ml})$, and cultured for 7 days. ${ }^{A} P<0.05$ compared with control. 
Table 3

In vitro estrogen treatment does not decrease T cell-produced TNF- $\alpha$

\begin{tabular}{lccc}
\hline & Sham & OVX & OVX estrogen \\
& T cells & T cells & T cells \\
No $17 \beta$ estradiol & $49 \pm 3$ & $151 \pm 12^{\mathrm{A}}$ & $53 \pm 6$ \\
$17 \beta$ estradiol $\left(10^{-8} \mathrm{M}\right)$ & $55 \pm 6$ & $146 \pm 14^{\mathrm{A}}$ & $58 \pm 8$ \\
& NS & NS & NS
\end{tabular}

T cells from estrogen-replete and OVX mice were cultured in phenol red-free medium and charcoal-stripped serum in the presence of $17 \beta$ estradiol $\left(10^{-8} \mathrm{M}\right)$ for 48 hours. The culture medium was then assayed for TNF- $\alpha$ using ELISA. Similar results were obtained by increasing $17 \beta$ estradiol up to $10^{-6} \mathrm{M}$ and the duration of the treatment to 72 hours (not shown). Data expressed as picograms per milliliter \pm SEM. ${ }^{A} P<0.05$ compared with sham and OVX estrogen.

Table 4

Ovariectomy does not increase T-cell apoptosis

\begin{tabular}{cccc}
\hline & Sham & OVX & OVX estrogen \\
T cells & T cells & T cells \\
Apoptotic T cells (\%) & $2.9 \pm 0.1$ & $3.8+0.1$ & $3.0 \pm 0.1$
\end{tabular}

T cells were purified from the bone marrow of OVX and estrogen-replete mice and cultured for 2 days. The percentage of apoptotic cells was then determined as described in Methods.

duction indirectly. To further investigate the mechanism by which $T$ cells from OVX mice secrete increased amounts of TNF- $\alpha$, unstimulated T cells were cocultured for 48 hours and their number counted at the end of the culture period. We found (Figure 5a) that the number of $\mathrm{T}$ cells was approximately threefold higher in cultures from OVX animals than in those from estrogen-replete mice. We also found that ovariectomy does not alter the number of cells undergoing apoptosis (Table 4), which suggests that ovariectomy increases Tcell proliferation. Attesting to the relevance in vivo of the regulatory effects of estrogen on T-cell proliferation, we found that bone marrow from OVX mice contained a larger number of $\mathrm{T}$ cells than that from estrogenreplete animals (Figure 5b). Together these data indicate that ovariectomy increases T cell-produced TNF- $\alpha$ by enhancing T-cell proliferation.

T cell-deficient mice are protected against the bone loss and the increase in bone turnover induced by ovariectomy. To investigate the relevance of $\mathrm{T}$ cells in the pathogenesis of ovariectomy-induced bone loss in vivo, we measured the BMD of the trabecular compartment of the tibia in euthymic and nude mice, 4 weeks after ovariectomy. We observed that while ovariectomy caused approximately a 30\% decrease in the BMD of euthymic controls, nude mice were completely protected against ovariectomyinduced bone loss (Figure 6a and 7). Further attesting to a contribution of $\mathrm{T}$ cells to bone homeostasis, BMD was approximately $20 \%$ higher in sham-operated nude mice than in sham euthymic controls (Figure 6a).

At 4 weeks after surgery, the urinary excretion of DPD, a marker of bone resorption that reflects both osteoclast number and activity (23), was approximately twofold higher in OVX euthymic controls than in estrogenreplete euthymic mice (Figure 6b). In contrast, OVX and estrogen-replete nude mice had similar urine DPD levels, a finding demonstrating that $\mathrm{T}$ cells mediate the effects of estrogen deficiency on bone resorption in vivo.

Since bone formation is coupled to resorption, the ovariectomy-induced increase in bone resorption is known to lead to an increase in bone formation. Accordingly, in euthymic controls, but not in nude mice, ovariectomy caused approximately a 50\% increase in the serum levels of osteocalcin, a marker of bone formation (24) (Figure 6c), further demonstrating that $T$ cells are pivotal for inducing the bone loss resulting from the effects of estrogen deficiency on bone remodeling.

\section{Discussion}

Estrogen prevents bone loss through multiple effects on bone marrow and bone cells, which result in decreased osteoclast formation $(4,5)$, increased osteoclast apoptosis (25), and decreased capacity of mature osteoclasts to resorb bone (26). Inhibition of osteoclast formation results primarily from the ability of estrogen to regulate the production of pro- and antiosteoclastogenic cytokines by bone and bone marrow cells $(4,5,21,27)$. Since $T$ cells are now recognized as estrogen-regulated cells capable of producing essential

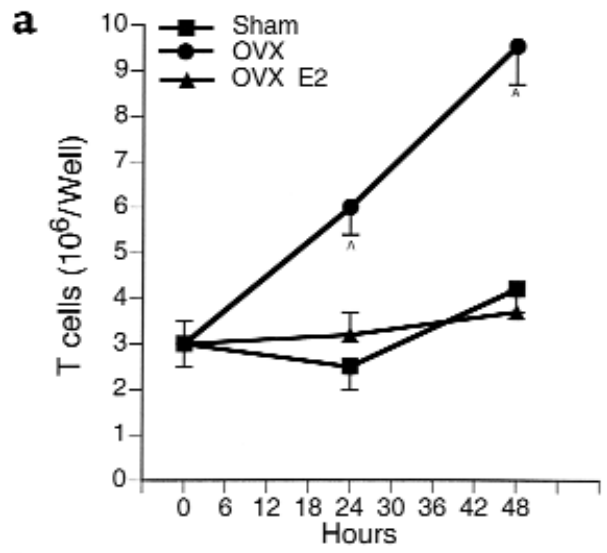

b

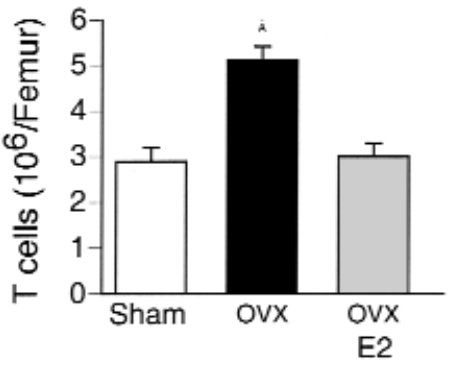

Figure 5

Ovariectomy increases T-cell proliferation and bone marrow T-cell content. Mean ( \pm SEM) of three independent experiments ( $n=6$ wells per group). ${ }^{A} P<0.05$ compared with baseline. (a) Unstimulated $T$ cells purified from OVX and estrogen-replete mice were cultured for 48 hours. At the end of the culture, T cells were counted. (b) Freshly isolated whole bone marrow was analyzed by FACS using antiCD90 Ab. Total number of bone marrow cells was counted. Results are expressed as number of T cells per femur. 
osteoclastogenic factors $(7,28)$, we have analyzed their contribution to the increased osteoclastogenesis and the bone loss induced by estrogen deficiency.

Bone densitometry and bone histomorphometry are established techniques for the detection of the bone loss induced by withdrawal of sex steroids. Analysis of bone mass by densitometry and histomorphometry correlates closely (29-33), although bone densitometry is not subjected to the sampling error that affects bone histomorphometry (34). Thus, in this study, bone density was measured in vivo by PQCT, a highly sensitive and precise technique that measures the density of the trabecular compartment of weight-bearing segments of the skeleton (18). The role of $\mathrm{T}$ cells in inducing osteoclastic bone resorption was assessed by measuring the urinary excretion of DPD, according to methods validated previously in the mouse (24). DPD excretion reflects both osteoclast number and osteoclast activity and correlates closely with histomorphometric indices of bone resorption (29).

We have found that ovariectomy failed to induce bone loss and stimulate bone resorption in T-cell deficient mice, thus demonstrating that $\mathrm{T}$ cells play a key role in mediating the bone-wasting effects of estrogen deficiency in vivo. Because $\mathrm{T}$ cell-deficient mice have normal bone morphology and only a modest increase in BMD, T cells are probably not required for normal bone remodeling. However, our results provide the first direct evidence that $\mathrm{T}$ cells cause the bone involution induced by estrogen deficiency.

Previous studies demonstrated neither the presence of a lower bone volume in nude mice (35) nor a failure of ovariectomy to induce bone loss in older athymic rats (36). However, in these earlier investigations bone volume was measured by bone histomorphometry, a lesssensitive technique than the densitometric method used in the current study (37). Moreover, mature athymic rats have a milder T-cell deficiency compared with young nude mice $(14,38)$ used in our investigation.

The data also demonstrate that $\mathrm{T}$ cells harvested from OVX mice produce TNF- $\alpha$ in an amount inadequate to induce osteoclast formation independent of RANKL, but sufficient to augment M-CSF- and RANKL-induced osteoclastogenesis through engagement of the TNF- $\alpha$ receptor p55. Additional studies in p55-deficient mice will be necessary to determine if the ability of TNF- $\alpha$ to stimulate bone resorption and induce bone loss in OVX mice is exclusively mediated by the $\mathrm{p} 55$ receptor.

Reports have shown that TNF- $\alpha$ at high concentrations $(\geq 20 \mathrm{ng} / \mathrm{ml}$ ) promotes osteoclast formation independently of RANKL, through NF- $\mathrm{KB}$ and Jun $\mathrm{NH}_{2}$-terminal kinase (JNK) activation $(6,39)$. Activation of these two signaling pathways is also responsible for the osteoclastogenic activity of RANKL $(40,41)$. Thus, it is likely that additive effects of RANKL and TNF- $\alpha$ on JNK and NF- $\kappa B$ activation accounted for the observed potentiating effect of TNF- $\alpha$ on RANKL- and M-CSF-induced osteoclastogenesis. Taken together, these observations provide a mechanism to explain how the small increase in T cell-produced TNF- $\alpha$ induced by estrogen deficiency leads to increased osteoclast formation and bone loss. However, since TNF- $\alpha$ stimulates the production of both M-CSF and RANKL $(6,42)$, our findings do not exclude the possibility that in conditions in which suboptimal levels of RANKL and M-CSF are present in the bone marrow, an additional mechanism by which $\mathrm{T}$ cell-produced TNF- $\alpha$ stimulates osteoclast formation is by increasing the production of these cytokines.

Another cytokine that has been implicated in the pathogenesis of ovariectomy-induced bone loss is IL-1 (43). Its level is increased in the bone marrow of OVX animals (15). Moreover, mice lacking the signaling IL-1 receptor IL-1R1 and animals treated with IL-1ra are protected against ovariectomy-induced bone loss $(44,45)$. IL-1 stimulates osteoclast activity through direct targeting of mature osteoclasts $(6,46)$, although it does not promote monocyte differentiation into osteoclasts (6). Thus, inhibition of TNF- $\alpha$ production accounts, at least in part, for the ability of E2 to block osteoclast formation, while the inhibitory effects of sex steroids on IL-1 production contributes to explain how E2 downregulates osteoclast activity.

a

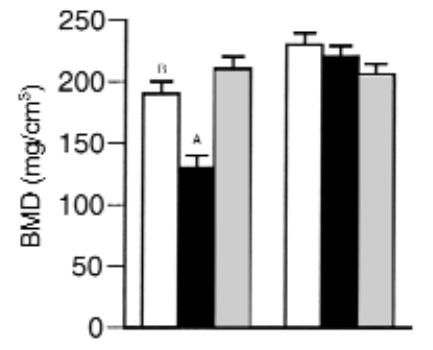

b

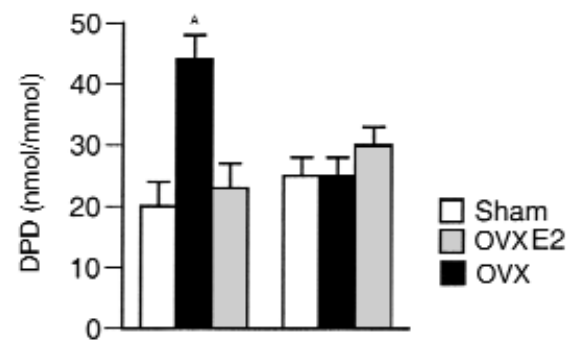

C

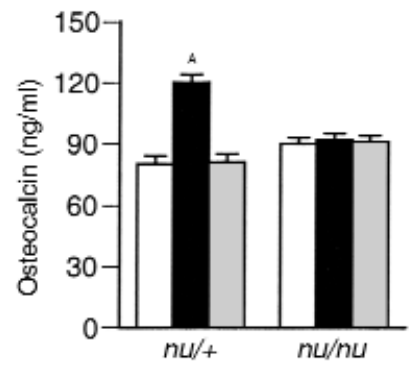

\section{Figure 6}

Ovariectomy fails to induce bone loss and upregulate bone turnover in nude mice ( $n=6$ per group). ${ }^{A} P<0.05$ compared with all other groups. ${ }^{B} P<0.05$ compared with sham $n u / n u$. (a) Trabecular BMD (mean \pm $\mathrm{SEM}$ ) of the tibia was measured 4 weeks after surgery in excised tibiae using PQCT. (b) DPD excretion (mean \pm SEM) at 4 weeks after surgery. (c) Serum osteocalcin levels (mean \pm SEM) at 4 weeks after surgery. 
A direct repressive effect of estrogen on IL-1 gene expression remains to be demonstrated. Moreover, studies have shown that TNF- $\alpha$ neutralization blocks IL-1 production, while IL-1 neutralization does not block TNF- $\alpha$ (47). Thus, it is likely that the increased bone marrow levels of IL-1 observed in OVX mice are, at least in part, a result of increased TNF- $\alpha$ production. When taken together, the available data indicate that while M-CSF and RANKL are essential for physiologic
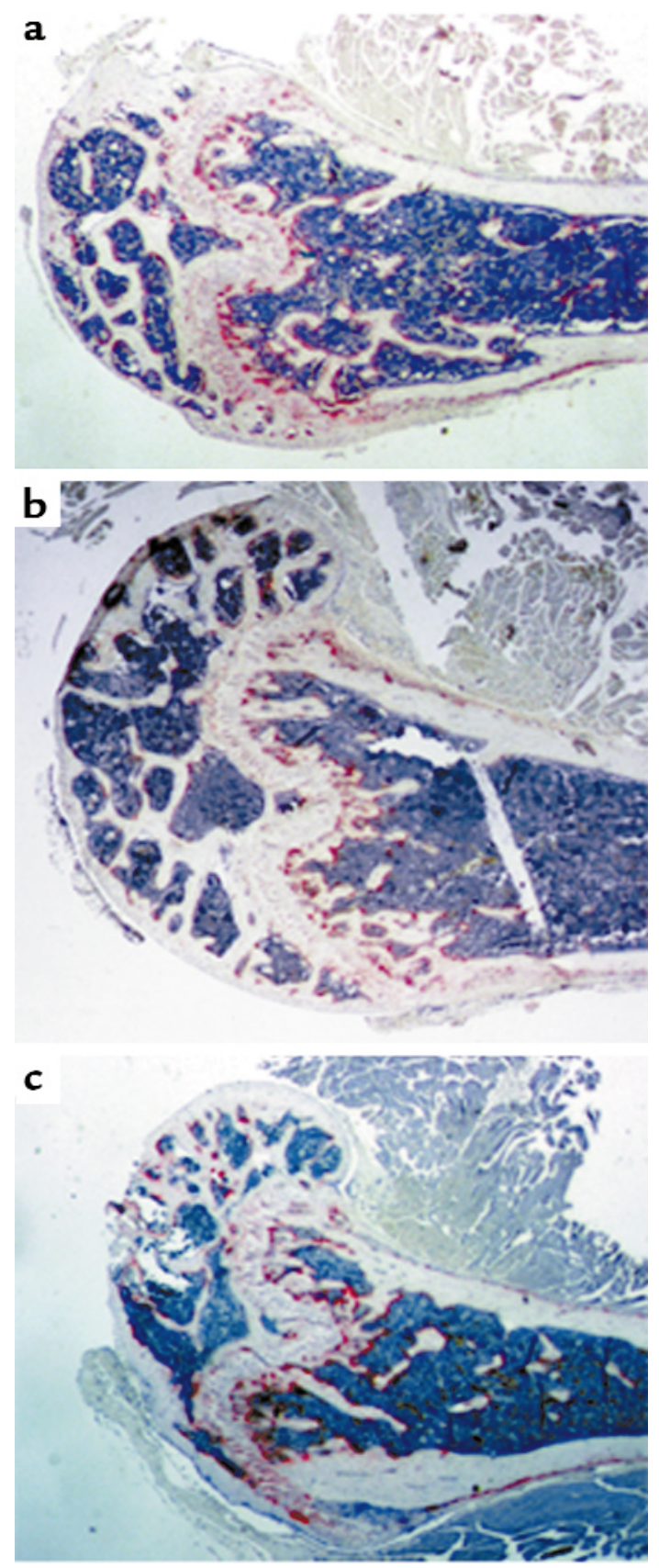

\section{Figure 7}

Histology of nude mice femur. Note that sham (top panel), OVX (middle panel), and estrogen-treated OVX (bottom panel) had similar cortical thickness and lack of trabecular bone resorption below the growth plates. The three groups had similar number of TRAPpositive osteoclasts (stained in red). osteoclast renewal (6) and RANKL is responsible for the bone loss associated with inflammation (7), TNF- $\alpha$ plays a key causal role in the bone involution characteristic of estrogen deficiency.

Previous studies by us and others had revealed that ovariectomy increases the production of TNF- $\alpha$ by unfractionated bone marrow and adherent mononuclear cells, a partially purified preparation of peripheral blood monocytes $(15,48,49)$. FACS analysis has now revealed that in estrogen-replete mice approximately $10 \%$ of adherent bone marrow cells are T cells and that ovariectomy increases their number approximately twofold. These findings are concordant with those of Abrahmsen et al. (50), who demonstrated that preparations of adherent mononuclear blood cells contain $\mathrm{CD}^{+} \mathrm{CD}^{+} 6^{+}$lymphocytes, a TNF- $\alpha$-producing subset of MHC-unrestricted adherent $\mathrm{T}$ cells. In that study the number of $\mathrm{CD}^{+} \mathrm{CD}^{+} 6^{+} \mathrm{T}$ cells was decreased by estrogen treatment and inversely correlated to bone density. Thus, earlier findings in bone marrow and adherent cell cultures are consistent with the stimulatory effect of estrogen deficiency on the Tcell production of TNF- $\alpha$ observed herein.

Our data indicate that ovariectomy increases the proliferation of unstimulated $T$ cells and the number of bone marrow $T$ cells, which suggests that in vivo estrogen may regulate the number of TNF- $\alpha$-producing $T$ cells, rather than TNF gene expression. The finding that in vitro estrogen treatment of cultured $\mathrm{T}$ cells did not blunt the ability of $\mathrm{T}$ cells from OVX mice to produce TNF- $\alpha$ is consistent with this hypothesis and suggests that estrogen deficiency acts indirectly, perhaps targeting a population of bone marrow cells capable of activating T-cell proliferation.

The existence of such a regulatory mechanism has been described in models of T cell-mediated delayedtype hypersensitivity, where estrogen has been found to suppress T-cell proliferation through targeting of antigen-presenting cells $(51,52)$. Similarly, previous reports from our laboratory demonstrated that estrogen represses stromal cell-soluble M-CSF production through targeting of IL-1- and TNF-producing bone marrow cells, rather than through a direct effect on mature stromal cells $(16,27)$.

The results of this study, together with previous reports that mice treated with a TNF- $\alpha$ inhibitor (53) or insensitive to TNF- $\alpha$ due to the overexpression of a soluble TNF- $\alpha$ receptor (54) are completely protected against ovariectomy-induced bone loss, are relevant for the pathogenesis and the treatment of postmenopausal osteoporosis, because identification of the cellular and molecular targets of estrogen in bone may lead to the development of new therapeutic agents for postmenopausal osteoporosis.

\section{Acknowledgments}

This study was supported, in part, by grants from the NIH (AR-41412 and AG-13534), the Eastern Missouri Chapter of the Arthritis Foundation, and The Lilly 
Centre for Women's Health. We wish to thank Andrey Shaw, Anthony Muslin, and Leonard Rifas for their expert review of the manuscript.

1. Lacey, D.L., et al. 1998. Osteoprotegerin ligand is a cytokine that regulates osteoclast differentiation and activation. Cell. 93:165-176.

2. Kong, Y.Y., et al. 1999. OPGL is a key regulator of osteoclastogenesis, lymphocyte development and lymph-node organogenesis. Nature. 397:315-323.

3. Yasuda, H., et al. 1998. Osteoclast differentiation factor is a ligand for osteoprotegerin/osteoclastogenesis-inhibitory factor and is identical to TRANCE/RANKL. Proc. Natl. Acad. Sci. USA. 95:3597-3602.

4. Manolagas, S.C., and Jilka, R.L. 1995. Bone marrow, cytokines, and bone remodeling. N. Engl. J. Med. 332:305-311.

5. Pacifici, R. 1996. Estrogen, cytokines and pathogenesis of postmenopausal osteoporosis. J. Bone Miner.Res. 11:1043-1051.

6. Suda, T., et al. 1999. Modulation of osteoclast differentiation and function by the new members of the tumor necrosis factor receptor and ligand families. Endocr. Rev. 20:345-357.

7. Kong, Y.Y., et al. 1999. Activated T cells regulate bone loss and joint destruction in adjuvant arthritis through osteoprotegerin ligand. Nature. 402:304-309.

8. Olsen, N.J., and Kovacs, W.J. 1996. Gonadal steroids and immunity. Endocr. Rev. 17:369-384

9. Bebo, B.F., Jr., Schuster, J.C., Vandenbark, A.A., and Offner, H. 1999. Androgens alter the cytokine profile and reduce encephalitogenicity of myelinreactive T cells. I. Immunol. 162:35-40.

10. Benten, W.P., Lieberherr, M., Giese, G., and Wunderlich, F. 1998. Estradiol binding to cell surface raises cytosolic free calcium in T cells. FEBS Lett. 422:349-353.

11. Gilmore, W., Weiner, L.P., and Correale, J. 1997. Effect of estradiol on cytokine secretion by proteolipid protein-specific $T$ cell clones isolated from multiple sclerosis patients and normal control subjects. J. Immunol. 158:446-451.

12. Fujita, T., Matsui, T., Nakao, Y., and Watanabe, S. 1984. T lymphocyte subsets in osteoporosis. Effect of 1-alpha hydroxyvitamin $\mathrm{D}_{3}$. Miner. Electrolyte Metab. 10:375-378.

13. Imai, Y., Tsunenari, T., Fukase, M., and Fujita, T. 1990. Quantitative bone histomorphometry and circulating $\mathrm{T}$ lymphocyte subsets in postmenopausal osteoporosis. J. Bone Miner. Res. 5:393-399.

14. Chen, W.F., Scollay, R., Shortman, K., Skinner, M., and Marbrook, J. 1984. T-cell development in the absence of a thymus: the number, the phenotype, and the functional capacity of T lymphocytes in nude mice. Am. J. Anat. 170:339-347.

15. Kitazawa, R., Kimble, R.B., Vannice, J.L., Kung, V.T., and Pacifici, R. 1994 Interleukin-1 receptor antagonist and tumor necrosis factor binding protein decrease osteoclast formation and bone resorption in ovariectomized mice. J. Clin. Invest. 94:2397-2406.

16. Srivastava, S., et al. 1998. Estrogen blocks M-CSF gene expression and osteoclast formation by regulating phosphorylation of Egr-1 and its interaction with Sp-1.J. Clin. Invest. 102:1850-1859.

17. Assenmacher, M., et al. 1998. Commitment of individual Th1-like lymphocytes to expression of IFN-gamma versus IL-4 and IL-10: selective induction of IL-10 by sequential stimulation of naive Th cells with IL-12 and IL-4. J. Immunol. 161:2825-2832.

18. Bucay, N., et al. 1998. Osteoprotegerin-deficient mice develop early onset osteoporosis and arterial calcification. Genes Dev. 12:1260-1268.

19. Seyedin, S.M., et al. 1993. Immunoassay of urinary pyridinoline: the new marker of bone resorption. J. Bone Miner. Res. 8:635-641.

20. Lea, C.K., Sarma, U., and Flanagan, A.M. 1999. Macrophage colony stimulating-factor transcripts are differentially regulated in rat bone-marrow by gender hormones. Endocrinology. 140:273-279.

21. Hofbauer, L.C., et al. 1999. Estrogen stimulates gene expression and protein production of osteoprotegerin in human osteoblastic cells. Endocrinology. 140:4367-4370

22. Tartaglia, L.A., and Goeddel, D.V. 1992. Two TNF receptors. Immunol. Today. 13:151-153.

23. Jilka, R.L., et al. 1998. Loss of estrogen upregulates osteoblastogenesis in the murine bone marrow. Evidence for autonomy from factors released during bone resorption. J. Clin. Invest. 101:1942-1950.

24. Blanque, R., Cottereaux, C., and Gardner, C.R. 1998. Increases in osteocalcin after ovariectomy are amplified by LPS injection: strain differences in bone remodelling. Gen. Pharmacol. 30:51-56.

25. Hughes, D.E., et al. 1996. Estrogen promotes apoptosis of murine osteoclasts mediated by TGF-beta. Nat. Med. 2:1132-1136.

26. Oursler, M.J., Osdoby, P., Pyfferoen, J., Riggs, B.L., and Spelsberg, T.C. 1991 Avian osteoclasts as estrogen target cells. Proc. Natl. Acad. Sci. USA. 88:6613-6617.

27. Kimble, R.B., Srivastava, S., Ross, F.P., Matayoshi, A., and Pacifici, R. 1996.
Estrogen deficiency increases the ability of stromal cells to support osteoclastogenesis via an IL-1 and TNF mediated stimulation of M-CSF production. J. Biol. Chem. 271:28890-28897.

28. Horwood, N.J., et al. 1999. Activated T lymphocytes support osteoclast formation in vitro. Biochem. Biophys. Res. Commun. 265:144-150.

29. Cenci, S., Weitzmann, M.N., Gentile, M.A., Aisa, M.C., and Pacifici, R. 2000. M-CSF neutralization and Egr-1 deficiency prevent ovariectomy-induced bone loss. J. Clin. Invest. 105:1279-1287.

30. Weinstein, R.S., Jilka, R.L., Parfitt, A.M., and Manolagas, S.C. 1997. The effects of androgen deficiency on murine bone remodeling and bone mineral density are mediated via cells of the osteoblastic lineage. Endocrinology. 138:4013-4021.

31. Rosen, H.N., et al. 1995. Differentiating between orchiectomized rats and controls using measurements of trabecular bone density: a comparison among DXA, histomorphometry, and peripheral quantitative computerized tomography. Calcif. Tissue Int. 57:35-39.

32. Helterbrand, J.D., Higgs, R.E., Jr., Iversen, P.W., Tysarczyk-Niemeyer, G., and Sato, M. 1997. Application of automatic image segmentation to tibiae and vertebrae from ovariectomized rats. Bone. 21:401-409.

33. Kuroda, S., et al. 1999. Anabolic effect of aminoterminally truncated fibroblast growth factor 4 (FGF4) on bone. Bone. 25:431-437.

34. Wright, C.D., et al. 1992. Combined inter-observer and inter-method variation in bone histomorphometry. Bone. 13:205-208.

35. McCauley, L.K., Rosol, T.J., Capen, C.C., and Horton, J.E. 1989. A comparison of bone turnover in athymic (nude) and euthymic mice: biochemical, histomorphometric, bone ash and in vitro studies. Bone. 10:29-34.

36. Sass, D.A., et al. 1997. The role of the T-lymphocyte in estrogen deficiency osteopenia. J. Bone Miner. Res. 12:479-486.

37. Parfitt, A.M. 1983. Bone histomorphometry techniques and interpretation. R.R. Recker, editor. CRC Press Inc. Boca Raton, Florida, USA. 143-224.

38. Festing, M.F., May, D., Connors, T.A., Lovell, D., and Sparrow, S. 1978. An athymic nude mutation in the rat. Nature. 274:365-366.

39. Kobayashi, K., et al. 2000. Tumor necrosis factor alpha stimulates osteoclast differentiation by a mechanism independent of the ODF/RANKLRANK interaction. J. Exp. Med. 191:275-286.

40. Hsu, H., et al. 1999. Tumor necrosis factor receptor family member RANK mediates osteoclast differentiation and activation induced by osteoprotegerin ligand. Proc. Natl. Acad. Sci. USA. 96:3540-3545.

41. Shevde, N.K., Bendixen, A.C., Dienger, K.M., and Pike, J.W. 2000. Estrogens suppress RANK ligand-induced osteoclast differentiation via a stromal cell independent mechanism involving c-Jun repression. Proc. Natl. Acad. Sci. USA. 97:7829-7834.

42. Sherman, M.L., Weber, B.L., Datta, R., and Kufe, D.W. 1990. Transcriptional and posttranscriptional regulation of macrophage-specific colony stimulating factor gene expression by tumor necrosis factor. J. Clin. Invest. 85:442-447.

43. Pacifici, R. 1998. Cytokines, estrogen and postmenopausal osteoporosis. The second decade. Endocrinology. 139:2659-2661.

44. Lorenzo, J.A., et al. 1998. Mice lacking the type I interleukin-1 receptor do not lose bone mass after ovariectomy. Endocrinology. 139:3022-3025.

45. Kimble, R.B., et al. 1994. Interleukin-1 receptor antagonist decreases bone loss and bone resorption in ovariectomized rats. J. Clin. Invest. 93:1959-1967.

46. Jimi, E., et al. 1999. Interleukin 1 induces multinucleation and bone-resorbing activity of osteoclasts in the absence of osteoblasts/stromal cells. Exp. Cell. Res. 247:84-93.

47. Feldmann, M., Brennan, F.M., and Maini, R. 1996. Rheumatoid arthritis. Cell. 85:307-310

48. Pacifici, R., et al. 1991. Effect of surgical menopause and estrogen replacement on cytokine release from human blood mononuclear cells. Proc. Natl. Acad. Sci. USA. 88:5134-5138.

49. Ralston, S.H., Russell, R.G.G., and Gowen, M. 1990. Estrogen inhibits release of tumor necrosis factor from peripheral blood mononuclear cells in postmenopausal women. J. Bone Miner. Res. 5:983-988.

50. Abrahamsen, B., Bendtzen, K., and Beck-Nielsen, H. 1997. Cytokines and T-lymphocyte subsets in healthy post-menopausal women: estrogen retards bone loss without affecting the release of IL-1 or IL-1ra. Bone. 20:251-258.

51. Salem, M.L., Matsuzaki, G., Kishihara, K., Madkour, G.A., and Nomoto, K. 2000. beta-estradiol suppresses T cell-mediated delayed-type hypersensitivity through suppression of antigen-presenting cell function and Th1 induction. Int. Arch. Allergy Immunol. 121:161-169.

52. Taube, M., Svensson, L., and Carlsten, H. 1998. T lymphocytes are not the target for estradiol-mediated suppression of DTH in reconstituted female severe combined immunodeficient (SCID) mice. Clin. Exp. Immunol. 114:147-153.

53. Kimble, R., Bain, S., and Pacifici, R. 1997. The functional block of TNF but not of IL- 6 prevents bone loss in ovariectomized mice. J. Bone Miner. Res. 12:935-941.

54. Ammann, P., et al. 1997. Transgenic mice expressing soluble tumor necrosis factor-receptor are protected against bone loss caused by estrogen deficiency. J. Clin. Invest. 99:1699-1703. 